\title{
THE THEORY OF INFLATION*
}

This important book by Professor Bent Hansen of the University of Uppsala is highly theoretical and abstract; yet it deals in detail with one of the most pressing practical problems of modern economic society: inflation and its control. The major substantive argument begins with a penetrating analysis of the theory of direct wage and price controls (Chapters IV, V, and VI). Repressed inflation is, however, considered only as "a special boundary case of open inflation". Although a full theory of open inflation is far more difficult than of repressed inflation, a simple theory of the former is also supplied (Chapter VII). This theory is related to fundamental problems in the theory of Walrasian general equilibrium (Chapter VIII), and to certain historical norms of monetary policy (Chapter IX). The latter two chapters deal primarily with problems of static equilibrium, and thus less directly with the economics of inflation. Despite their undoubted interest to the pure theorist, we shall therefore concentrate this brief review on some aspects of the earlier chapters.

Professor Hansen's analysis is rooted in the generally familiar "Swedish approach", which distinguishes ex ante and expost magnitudes of economic variables. The analysis is, however, carried far beyond the simplified Swedish systems previously available (at least in English). Particularly, in dealing with inflationary situations, Hansen finds it necessary to dispense with the usual Swedish assumption that purchase plans are carried out, with an excess of ex ante investment over saving resulting either in unplanned decreases in stocks or unexpected increments of income (and saving). Instead, he substitutes the assumption that plans of factors for the sale of their services are carried out-plans which may be inconsistent with the expected factor purchases of entrepreneurs. With this change, the analysis of inflation in terms of an excess of investment over saving loses much of its usefulness. This step permits the introduction of independence between factor and commodity markets, and the analysis of many common inflationary situations, including particularly the disappointment of entrepreneurial sales (and income) expectations resulting from the existence of "labor shortages".

Upon his Swedish definitional stem (set forth in Chapter II) Hansen grafts various structural or behavioral relationships (particularly consumption propensities and cost functions), to produce several different "models". Although the treatment throughout is rigorous and at points highly mathematical, the patient non-mathematical reader can make substantial headway, with the aid of clear and novel graphical presentations of many of the most interesting points.

Hansen appears to consider his most important contribution to the analysis of inflation to have been the explicit introduction of a factor (labor) market, in which a gap between demand and supply can exist side-by-side with (and to some extent independently of) an inflationary gap in the commodity markets. It is in this major respect that he believes his analysis expands the Keynesian treatment of inflation. He characterizes the latter as an analysis in which "it is

- A review note of $A$ Study in the Theory of Infation. By Bent Hansen. Allen \& Unwin, London I951. Pp.xiii + 262.s. 21/-. 
only in the commodity markets that excess demand appears as the driving force behind price increases; the factor markets ... are dealt with simply by assuming full employment, and nothing more" (p.19). Wage increases, in the Keynesian analysis, result essentially from union pressures to keep up with (or get ahead of) the rise in commodity prices.

Although the reviewer will agree that the Keynesian analysis of inflation often pays meager attention to supply-and-demand forces in the labor market, he does not believe that Hansen's point is entirely well taken. Keynes' assumptions of profit-maximizing behavior and diminishing returns, which he shares with the Classical system, certainly mean that excess demand in the commodity markets would reflect itself-through the employers' demand for labor function-in excess demand in the factor markets; and the reviewer, at least, has always so interpreted the Keynesian system. To be sure, wage rates are largely independent of supply and demand factors in conditions of less-than-full employment; but with full employment, Keynes' own discussion (e.g., in Chapter 23 of the General Theory) clearly implies that wages will be bid up (along with prices), to maintain the real wage appropriate to the full employment level of output. What the Keynesian system does not envisage-because its dynamic structure is not explicitly formulated-is that the excess demands in the two markets may, to some extent, be independent of one another. Hansen's apparatus permits of this separation, and thereby advances our understanding considerably.

The preceding remarks are made only because of Hansen's repeated emphasis upon this difference between his own and the Keynesian discussions. Actually, even if the reviewer is correct, this detracts not at all from the originality and importance of Hansen's analysis.

The essence of Hansen's treatment of repressed inflation can be had from the following algebraic analysis (derived and simplified from Hansen's).

We assume perfect competition in product and factor markets (Hansen also treats fully the case of "monopolism"), with the money wage legally fixed at $w$ and the controlled price level at $p$.

Given their production function(s), entrepreneurs would maximize profits by hiring an amount of labor $L_{0}$, producing a quantity of output $Q_{0}$, which (assuming, in this case, the desire and ability to maintain constant inventories) also equals expected sales. Entrepreneurs' expected (gross) income is thus $p Q_{0}-w L_{0}$.

Workers, however, plan to make available $L_{\mathrm{I}}$ of labor $\left(L_{\mathrm{I}}<L_{0}\right)$, which will permit aggregate production of $Q_{I}\left(Q_{1}<Q_{0}\right)$. Workers' expected (and realized) income is thus $w L_{\mathrm{I}}$.

Based upon expected incomes, $p Q_{0}-w L_{0}$, and $w L_{1}$, and given the consumption propensities of the two groups, and the amount of planned investment, planned purchases will aggregate the quantity $D_{0}$ (where $D_{0}>Q_{0}>Q_{I}$ ). (Here we assume that "planned purchases" are identical with "active attemps to purchase"which might include duplicated orders-and in turn identical with "optimum purchases"- the amount given by functional propensities. The possibility of differences is also considered.)

Actual sales and income are $p Q_{\mathrm{I}}$, of which workers receive their expected 
$w L_{I}$, while entrepreneurs' actual income $\left(p Q_{\mathrm{I}}-w L_{\mathrm{I}}\right)$, is below expectations by the amount $\left(p Q_{0}-w L_{0}\right)-\left(p Q_{1}-w L_{1}\right)$.

The "inflationary gap in commodity markets" is $p\left(D_{0}-Q_{I}\right)$, which can be seen to be greater than the "ex ante commodity gap", $p\left(D_{0}-Q_{0}\right)$. The "factor gap" is $w\left(L_{0}-L_{1}\right)$. It can also be seen that the inflationary gap equals the sum of the $e x$ ante commodity gap, the factor gap, and the unexpected loss of entrepreneurial income:

Inflationary gap Ex ante Com- Factor gap Unexpected loss

$$
\overbrace{p D_{0}-p Q_{\mathrm{I}}}=\overbrace{\begin{array}{c}
p D_{0}-p Q_{\mathrm{O}} \\
p D_{0}-p Q_{\mathrm{I}}
\end{array}}^{\text {modity gap }}+\overbrace{w L_{0}-w L_{\mathrm{I}}}+\overbrace{\left(p Q_{0}-w L_{0}\right)-\left(p Q_{\mathrm{I}}-w L_{\mathrm{I}}\right)}^{\text {of entr. income }}
$$

We can also see the relation of these magnitudes to ex ante saving, $S_{0}$, and $e x$ ante investment, $I_{0}$, by noting that

$$
\begin{aligned}
& p D_{0}=C_{0}+J_{0}, \text { or } \\
& I_{0}=p D_{0}-C_{0} \\
& S_{0}=p Q_{0}-w L_{0}+w L_{\mathbf{I}}-C_{0}
\end{aligned}
$$

The difference between $I_{0}$ and $S_{0}$ is thus given as:

$$
I_{0}-S_{0}=p D_{0}-p Q_{0}+w L_{0}-w L_{\Upsilon}
$$

which can be seen to be equal to the $e x$ ante commodity gap plus the factor gap. It can be shown that $S_{0}$ may exceed $I_{0}$, yet an inflationary gap remain in both commodity and factor markets.

With this apparatus Hansen then considers such questions as (a) the effect of direct taxes sufficient to remove the inflationary gap in commodity markets (this may nevertheless leave a factor gap); (b) the "red policy" of freeing wage controls and retaining price controls (which eliminates the factor gap but may either increase or decrease the commodity gap); (c) the "liberal policy" of controlling wages and removing price controls (which will always increase the factor gap, but may increase or decrease the commodity gap); (d) a decrease in productivity (which, if "permanent" and does not lead to higher price ceilings, will reduce the factor gap, either increasing or decreasing the commodity gap); etc. Under "monopolism" the results in each case may or may not be the same.

The analysis of open inflation is complicated by the necessity to assume dynamic relationships (as opposed to the essentially static assumptions of the repressed inflation analysis). Using a somewhat simpler analytical frame, and making the rate of price change depend on the degree of excess commodity demand and the rate of wage change upon the degree of excess labor demand, Hansen shows that a "quasi-equilibrium" wage-price ratio will be attained, which will be affected, as will the speed of the inflation, by changes in (a) government demand, (b) direct and indirect taxes, (c) productivity, (d) "cost-of-living" wage adjustment formulae, etc.

Throughout, the analysis is highly theoretical and uniformly rigorous. Although the reviewer might occasionally quarrel with the appropriateness of assumptions, he found no slip of logic. The author makes no pretense at an exhaustive treatment of inflation, which "would have to cover the whole of the field 
of theoretical and empirical economic dynamics". His concentration upon theory is deliberate, and he freely admits that "the relations with empirical facts are quite platonic". While some will argue that analysis at this abstract level is quite worthless, this reviewer vigorously disagrees. All discussion of inflation, its cause and cure, is based upon some theoretical frame, and the firmness with which particular policy recommendations are advanced often seems to be positively correlated with the naiveté of the analysis.

In the reviewer's opinion Hansen's volume makes definite contribution to our understanding of inflation and therefore to our ability to deal more successfully with its threat to our society.

In conclusion, it should be noted that the book is most attractively set up, with many clear diagrams, with mathematical symbols clearly printed and easily identified, and typographical errors rare. The translator, Mr. R.S. Stedman, deserves credit for the effective and lively English style.

University of Michigan

Gardner Ackley Ann Arbor, Mich. (U.S.A.) 